\title{
Community-Based Technology Co-Design: Insights on Participation, and the Value of the "Co"
}

\author{
Pedro Reynolds-Cuéllar \\ Massachusetts Institute of Technology, Cambridge, MA \\ pcuellar@mit.edu
}

\begin{abstract}
Evidence and analysis of Community-Based Participatory Design (PD) and Co-Design programs are not abundant. Filling this gap allows for better understanding of (1) the value programs offer from a quantitative standpoint, and (2) how to formalize participation within PD. In this paper, we present evidence from a series of International Development Design Summits (IDDS), a PD-oriented program focused on low-cost technology co-design and co-production, in collaboration with local communities. The purpose is to provide opportunities for learning and practicing community-based PD in an intercultural setting. We examine data from five summits in Colombia between 2015-2018. We discuss the value of this approach across multiple groups, and how it can be understood as a measure of participation. We present evidence of participant benefits, including an exploratory analysis of self-perception using sentiment analysis. Finally, we discuss the challenges and potential directions for this work. This paper contributes to further understand the value of participation (the "co") in the context of community-based PD.
\end{abstract}

\section{CCS CONCEPTS}

- Human-centered computing $\rightarrow$ Interaction design; Interaction design process and methods; Participatory design.

\section{KEYWORDS}

Participatory Design, Co-Design, Participation, Design Practice

\section{ACM Reference Format:}

Pedro Reynolds-Cuéllar and Daniela Delgado Ramos. 2020. CommunityBased Technology Co-Design: Insights on Participation, and the Value of the "Co". In Proceedings of the 16th Participatory Design Conference 2020 Participation(s) Otherwise - Vol 1 (PDC'20: Vol. 1), fune 15-20, 2020, Manizales, Colombia. ACM, New York, NY, USA, 10 pages. https://doi.org/10.1145/ 3385010.3385030

\section{INTRODUCTION}

Participatory Design (PD), and other design approaches allowing for inclusive ways of participation, have become a common component in educational programs in design and engineering: Engineers

Permission to make digital or hard copies of all or part of this work for personal or classroom use is granted without fee provided that copies are not made or distributed for profit or commercial advantage and that copies bear this notice and the full citation on the first page. Copyrights for components of this work owned by others than ACM must be honored. Abstracting with credit is permitted. To copy otherwise, or republish, to post on servers or to redistribute to lists, requires prior specific permission and/or a fee. Request permissions from permissions@acm.org.

PDC '20: Vol. 1, June 15-20, 2020, Manizales, Colombia

(c) 2020 Association for Computing Machinery.

ACM ISBN 978-1-4503-7700-3/20/06 . \$ \$15.00

https://doi.org/10.1145/3385010.3385030

\author{
Daniela Delgado Ramos \\ University of Illinois, Champaign, IL \\ dd6@illinois.edu
}

Without Borders provides field practice, and community engagement opportunities for engineers and designers around the world $[17,31]$. The MIT D-Lab engages designers in creating practical solutions to poverty challenges, together with members from communities around the world [34]. Similarly, the d.school at Stanford, and the Olin School of Engineering, provide courses focused on connecting and facilitating a process where students can address design and engineering issues along with communities [35, 44]. It is worth mentioning that literature on what is known as "service learning" also points to community-based work. However, its focus is on the value of this interaction for students' learning and curriculum design, rather than on the participatory dimensions of the work. In the context of the academic literature, specific case-based $\mathrm{PD}$ projects on technology design utilizing participatory methods, are commonly explored in venues such as Computer-Supported Cooperative Work (CSCW), Computer-Human Interaction (CHI) and Participatory Design (PD) $[8,15,42]$. This body of work frequently emphasizes analysis of case studies in the field, discussing theory, methods, and results in relationship to a one-shot instance. Notably, Manzini \& Rizzo provide a multi-case analysis of citizen-oriented $\mathrm{PD}$, observing the need to expand the scope of PD in this context, as well as the role of designers in such processes [32]. Christiansson et al., presents an account of five iterations of a PD course using live projects, and discusses the potential, and challenges of PD education at large scale [9]. However, these studies do not address the value of each program across different actors, nor from a quantitative standpoint. Instead they focus on comparative analysis, deriving insights from particular approaches taken. Filling this gap, particularly in the context of community-based work, is critical. As Cleaver rightfully points, further evidence around the effectiveness of co-design as a strategy for social change, is to be provided [10]. Our paper is a step in this direction.

One common trend in single and multi-case analysis studies, is the search for understanding how participation unfolds. In their extensive survey of the work done on this area from within the PD community, Halskov and Hansen call for increased attention around how participation unfolds, pointing to the value of longitudinal studies of participatory design processes [25]. Our paper aims to begin filling this gap, by providing detailed accounts of how participants of five iterations of a community-based PD design program perceived its value, using a variety of mixed-methods techniques.

The International Development Design Summit (IDDS) program is a multi-stakeholder community-based PD program mobilized under the leadership of the MIT D-Lab at the Massachusetts Institute of Technology (MIT). The program is an intense, practical experience that gathers together diverse groups of people to co-design technological solutions to issues of importance to local 
communities. IDDS summits are held in historically marginalized communities around the world, and usually last between 3-4 weeks. During this time, participants from all over the world, and from different backgrounds, work on a variety of projects, the majority of which are technology-based. Each summit is preceded by a several months long community engagement process, and followed by a series of continuity strategies such as follow up projects, and design education events among others. The program started in 2007 and, to date, it has seen 24 iterations in 13 different countries, with more than 800 participants. As a community-based program, its methodology differs from traditional programs in higher education. Curriculum is geared towards audiences at different levels of education, including illiterate participants, and caters to a large spectrum of intercultural exchange. Its instruction approach relies heavily on hands-on methods, and is inspired by PD, psychological, and design theory components. This paper reflects on how these, and other aspects of the program, impacted participants across different dimensions, and across different groups.

The contribution of this paper is therefore two-fold. First, we provide a multi-dimensional, longitudinal and primarily quantitative analysis of a community-based program in PD, shedding light into the how these kinds of programs unfold and can be evaluated. Second, by looking across different dimensions of analysis, we offer an insight into the value of participation (the "co"), and how it unfolds in the context of community-based PD programs.

In what follows, we introduce the IDDS program. Its theoretical framework, related work, and the methods used to develop this paper. The following sections, present and discuss empirical findings, with a last section of conclusions and reflections that closes the work.

\section{THE IDDS PROGRAM}

The International Development Design Summit (IDDS) is a multistakeholder community-based PD program developed by the MIT D-Lab, the Olin College of Engineering, and the California Institute of Technology, Caltech, under the leadership of Amy Smith [26]. The program has been implemented 24 times to date, and its main purpose is to introduce participants to fundamental aspects of theory and practice of PD. The program has long and short versions ranging from two-weeks, all the way to five and a half weeks. Between 2007 and 2014, the program held primarily a yearly edition taking place in countries like Ghana, Zambia, Tanzania, Brazil and the United States, among others. The make-up of instruction within each summit, typically consists of 10-hour long working days, with one to two full resting days per week of work. Summits are commonly implemented from within partnering communities; each summit houses between 40-60 participants, organized into teams ranging between 4 and 8 people, each of which is supported by one or two design facilitators. Each IDDS theme is selected based on prior fieldwork carried out by members of the summit's organizing team. Upon arrival, international, local and community participants start collaborating, based on prior research conducted by the summit organizing team, surfacing opportunities and/or challenges are then presented to the group of participants, for them to choose which one they will work on for the rest of the summit.
Based on selections, between 6-10 teams are formed. During a regular working day, participants work on a variety of hands-on PD design, action research, reflection, and intercultural collaboration activities, in relationship to each team's project. The layout of each summit varies according to its objectives, resources, and timeline. Summits can be divided into stages, marked by key moments such as community visits, traditionally with home stays. They can also be run entirely from within communities and organized around key learning objectives. Regardless of this variance, first stage is focused on building a strong foundation for relationships between participants, participants and community members, and between teams and their design facilitators. These relationships are the cornerstone of the rest of the program. The remaining of the first stage is comprised of hands-on sessions, providing context around each challenge or opportunity, and building the technical and methodological design foundations for each team to navigate the rest of the program. The second stage, begins with the first community visit (in the case that the program is not being hosted within the community itself). This fieldwork-based part of the curriculum, is orchestrated in collaboration with community members embedded in each team, making them, in many ways, the team facilitators during this part of the program. Following the first community visit, participants are provided with technical, and methodological tools, as well as with physical materials, to engage in prototyping, production, and assessment of a series of models. During this part of the process, community members act both as part of the team, but also as community liaisons. Lastly, the third stage of the program, focuses on the co-design and co-production of a full scale, functional technology prototype. During this last stage, teams are supported by the organizational staff as they build prototypes that meet the basic technical requirements in their co-productions. What we refer to as co-productions, are the final prototypes produced by each team as an outcome of the program. Each team is assigned a budget, and assisted by design facilitators and a Lead Facilitator, team members procure materials for their prototypes. The program closes its curriculum with an open fair that brings together community members around the projects, while providing a space for communities to showcase other local products. Later summits are adding a continuity planning stage to provide longevity to the process.

Methodological aspects of the program can be followed by participants using a Design Workbook, specifically designed by design instructors at MIT D-Lab and Olin college with feedback from a global community of IDDS-related designers. The workbook lays out each step of a version of the design process, provides case study examples, and allows for participants' documentation of their own design process. Communities are either self-selected, or approached based on existing processes connected with members of the organizing team. Each year, the core curriculum is updated to reflect the connection with each year's program theme. Also, using data collected through surveys, sessions within the core curriculum are updated to reflect feedback and insights from both participants, and design facilitators.

Participants work in groups from the onset of the program, mostly around their projects. The first stage of the program is the most intense with regards to instruction, with a few lectures and several hands-on sessions on methodology running between 

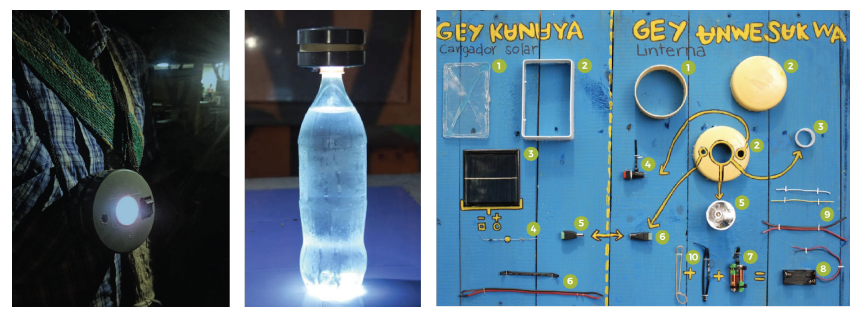

Figure 1: Portable multi-modal low-cost solar lantern. IDDS New Coastal Territories, 2018. a) portable mode. b) lamp mode. c) instructable board.

early morning, and early afternoon. The second and third stages of the program, are more focused on teamwork, orchestrated by design facilitators within each team. The role of these facilitators is to provide methodological guidance, to manage team dynamics, to be a link to the organizing team, and to ensure continuous opportunities for cross-pollination, and collaboration both within the community, and between teams. It is worth mentioning that IDDS is a volunteer-run program, with past participants acting as members of organizing teams, therefore providing opportunity for others to be exposed to the methodology.

The criteria for project outcomes have been constant around the co-design and co-production of technologies, with certain exceptions where teams identified more impactful interventions that did not require any technological development. Once a project is completed, teams submit a report that documents aspects of cultural context, design process, technical design, user testing, plans for continuity, insights and lessons learned. Examples of partnering communities include: local government units, and informal community associations within groups such as coffee farmers, indigenous peoples, fishermen, and guerrilla ex-combatants. Examples of projects developed within the program include: recycled plastic extruders (developed in partnership with waste-picker associations, Arduino-based soil fertilizer testers, and portable solar lanterns (shown in Figure 1).

Efforts to formalize project continuity as part of the core curriculum have been made, including continuity worksheets and specific curricular elements. Given this variance, there are a variety of examples of how projects (co-productions), participants, and/or community members remain involved with the program. These unintended outcomes will be discussed in our empirical findings section.

\section{THEORETICAL FRAMEWORK}

Historically, the focus of the IDDS program has been on co-creation. This is the term that IDDS' founder, Amy Smith [26] has been championing since the inception of the program in 2007. Taken in its practice, the term does not differ significantly from what is reported as co-design and PD across case studies in both these fields' literatures [32, 38]. For the purpose of this paper, and following Sanders \& Stappers [38], we will refer to the practice of IDDS as co-design. It is important to note that, because one of the guiding principles of the program is its inherent capacity to be taught to anybody regardless of their level of education, there is little focus on theory throughout the curriculum used at IDDS. That said, activities that make the learning arc of the program are all informed by political, philosophical, and learning aspects, as we note in section 3.1 and 3.2 .

During the program, participants are introduced to fundamental concepts of design and PD through case studies [30,39], and to the concept of a design cycle, using a variety of methods later falling into a model called Creative Capacity Building [46]. This methodology for teaching design is complemented with a set of activities, catering to promote intercultural collaboration (e.g. design challenges [37], community visits, morning circles, and collective cooking), the breakage of historical power dynamics across class, education, culture, age and gender, as well as to disrupt the classic user vs. designer dyad [4]. Since its inception, the IDDS program has made a conscious decision to favor technology-based projects. Under the "less papers, more prototypes" ethos, the program has chosen to focus on the practice of design as its main learning vehicle. Designing and building technology provides a concrete, selfcontained environment to promote changes in mindset, provide technical and methodological skills, as well as to learn and to practice a variety of soft skills. Even though the program acknowledges non-technological approaches are necessary, it has chosen technology design as its main instrument for change, in part due to limited literacy in the audiences it reaches, and also due to the academic background of some the early IDDS creators.

\subsection{The Creative Capacity Building Approach}

Following the inaugural IDDS program in 2007, and through integration of lessons learned, concepts informing the curriculum began to develop into political, learning, and development principles, later articulated in what is known today as the Creative Capacity Building (CCB) methodology. Described by Taha back in 2011 [48], and based on Amy Smith's academic and practical experiences, the framework is presented as an amalgamation of constructs tracing from Gandhi's early criticisms of industrialization, to 1970's "buddhist economics", contending the irrationality of acting as if "goods as more important than people and consumption as more important than creative activity" [40]. It also presents the methodology as an expression of new ideas within the development and education fields. Ideas from economist Amartya Sen around the conceptualization of basic needs [45], Freire's fundamentals of social transformation through popular education [20], and frameworks for reflective practice that allow for the creation of dynamic knowledge flows [39], form the philosophical base of the CCB model. Taken together, these aspects of the methodology speak to an important concept motivating the implementation of the program in Colombia: self-determination. Formally discussed for the first time in 1961 as part of the "Declaration of the Granting of Independence to Colonial Countries and Peoples" within the United Nations (UN) $[12,14]$, the concept formalizes the right of all peoples to define key aspects of their development. The declaration states that "all peoples have the right to self-determination; by virtue of that right they freely determine their political status and freely pursue their economic, social, and cultural development". This right was later reaffirmed by the Helsinki Final Act of 1975 [19], and since then has been further theorized, primarily within the 
context of aboriginal and indigenous peoples' rights. A common notion, presents self-determination as both internal (decisions over economic, cultural, and political aspects), and external (liberation from foreign ruling) [13]. This idea is central to IDDS within the Colombian context, particularly given the country's multicultural richness, and has informed decisions pertaining the implementation, and further continuity of the program. It also helps connect the findings we report in this paper with the type of change the programs seeks to foster.

\subsection{Constructionist Learning Theory}

Because of its inherent bias towards practice, the IDDS program, as well as the CCB methodology, can be situated within a constructivist learning tradition, in the lines of Dewey's experiential education [28]. However, since the main educational vehicle within the IDDS model is co-design of a functional technological prototype, the approach to the implementation of the program in Colombia is informed by constructionist views. Constructionism is rooted in $\mathrm{Pi}$ aget's seminal ideas in cognitive development, particularly around the assimilation and accommodation of prior experience and knowledge [6], and Vigotsky's later positioning of social constructivism as an observation of the role of social interactions in the making of knowledge [29]. Using these notions, Papert developed a model for learning, and embodies it in the action of making, or learning with technology [1]. In particular, Papert's foundational Eight Big Ideas [43] are of special influence to our practice of PD, and to the work depicted in this paper. Also rooted in philosophy, politics, and education, his ideas were expressed, similar to Freire's, in practical, actionable terms. In that sense, the theoretical foundations of the IDDS program are embodied in a 'praxis', in the Freirean sense of the word [20], allowing participants to express and act upon their knowledge, both at the individual and collective levels.

\section{RELATED WORK IN COMMUNITY-BASED PD}

Systematic quantification of PD program outcomes is an underresearched area within the PD literature. Previous work in this direction, has been concentrated in the application of communitybased PD in the context of health research and practice. Israel et. al., surveys several "community-based approaches to public health" initiatives, ranging from health programs on prevention and treatment of disease, to participatory inclusion programs within marginalized Black and Latino communities [16, 18, 27, 33]. This body of work has been complemented with the appearance of case studies, and multi-case studies, shedding light into how PD programs can be studied in the context of community work, from both quantitative and qualitative perspectives [8, 32, 47]. Notable examples of this work include ICT4D community-based programs on digital education, accessibility, and online communities [5, 21, 48], as well as participatory planning projects [2], and access to basic services $[41,42]$.

One key theme arising from this literature, is the need for further exploration and understanding of the notion of participation. This is another gap in the literature, as noted by Andersen et. al. [3]. This notion is central, since it provides a useful framework for understanding the value of community-based PD programs, as well as a springboard to drive insights on how such programs evolve. Sabiescu et.al., for example, defines participation in the context of $\mathrm{PD}$, and development work, as the "space between the designer's and local views of participation" [36]. Under this view, participation can be viewed as having two distinct approaches: instrumental (related to the advancement of local support for a program, and transformative (related to the building of local capacities, empowerment and ownership). Sabiescu calls for a broadening of what she reads as the traditional instrumental approach in PD. Andersen on the other hand, situates participation in a two-concept construct with participation as existent, only partially, through a range of activities related to a PD project, and as an action that includes networks of networks, and not just individuals [3].

\section{METHOD}

Our work builds upon data collected at five IDDS programs implemented in Colombia (2015, 2016, 2017, and two in 2018). The program began its implementation in Colombia in 2015 as part of an effort to expand its geographical reach and presence in Latin America. Implementations of the program in Colombia followed the tradition of bringing together participants from all backgrounds and walks of life, making sure it opened space for academic, practice and ancestral types of expertise, among others. Data collection was systematic from the following IDDS programs: Zero Waste, 2015 (ZW), Education, 2016 (ED), Climate Change Adaptation, 2017 (CCA), Building Peace, 2018 (BP), and New Coastal Territories, 2018 (NCT). The instrument used to collect data was a self-perception survey, designed at the MIT D-Lab, and administered to participants at three stages during each summit: at the beginning of the program (Day 1, 25 questions), at mid-point (Day 9, 14 questions), and at the end of the program (Day 17, 16 questions). $79 \%$ of the surveys were administered via digital form, $16 \%$ via paper and $5 \%$ in the form of a structured interview. These methods were chosen to account for literacy levels both digital and traditional. The survey is comprised of three main topics: 1) "Objectives and Aspirations," surfacing participants expectations, and later impressions of the program; 2) "Learning," allowing for self-assessment of progress in technical and methodological skills; and 3) "Feedback," eliciting participants reporting on their experience with curriculum, logistics, and infrastructural aspects of the program. These topics are a reflection of three different areas foci of IDDS theory of change across outputs, learnings and takeaways, and outcomes. Finally, we selected specific questions of the survey where perception of values was directly reported in relation to summits, projects and teams. Questions that were consistent across summits, and could reflect participants' progress or change were of particular interest. Therefore, we considered only a portion of the survey, overlooking most information related to logistics.

In order to perform our analysis, we assembled a dataset with information from 236 participants across all five programs, and added annotations related to each program, including theme, year, and field of work of both the program and the projects. Data regarding participants' further involvement with the program was collected directly by authors in preparation for this paper. Figure 2 presents the demographic distribution of participants in each summit, where an average of 40 people took part in. Figure 3 presents participants' 
aggregate distributions across gender, age and the stakeholder sector they were affiliated with. On the survey, if a participant was part of the community, it was formally addressed as the sector of affiliation instead of the participant's origin. Yet, in order to perform this analysis, the authors decided to unify these characteristics and group the participants in three big categories, Community, National, and International. For this classification, the national includes locals that are not part of the central community where the summit was based on, but live in a close geography. This decision sought to identify the value perceived from community members (community), those living in geographical proximity to communities (national), and external agents with less shared context (international). The final sample consisted of 61 community participants, 97 national participants, and 66 international participants for a total of 224. For our analysis of the value of participation (the "co-"), we use the lens of three key actors in the program: participants, communities and co-productions. We include co-productions as part of our optics of analysis, given how prominent the prototyping aspect is for the entirety of the program. For the purpose of our analyses, we take all community members that participated in the program as one constituency: communities. Findings across outcomes for these three groups, including a reflection on unintended outcomes are included in our empirical findings section (section 6).

\section{EMPIRICAL FINDINGS}

One of the distinctive features of the IDDS program, is its expressed intention to bring together a constellation of stakeholders. This group can be comprised of, but not limited, to local communities, local, national and international participants, universities, government units, private companies, NGOs, and social innovation and design practitioners. We take inspiration from Gärtner and Wagner's framework of arenas of participation [22], and describe our findings with regards to outcomes of the program across three different groups: participants (individual arena), communities (national arena), and co-productions (company arena). In the same vein, and following Boosen's [7] User Gains classification, we report findings regarding skills learned throughout the program can in terms of personal and professional gains, collaboration gains, and sustainability gains.

\subsection{Value of the program to participants}

What can be said about the value of the program for its participants? In order to answer this question, we focus primarily on skills, using two datapoints: (1) participants perceptions regarding their skills before the program and, (2) after the program. This structuring corresponds with how the evaluation instrument was structured, as explained in our methods section. In order to untangle the value driven by participants through the IDDS co-design experience, we analyzed our data segmenting between community members, national, and international participants.

We chose this geographical-based grouping since one of the main goals of the IDDS program in Colombia, is to provide as much value as possible to partnering communities. Therefore, a mechanism to disentangle the value they get out of the program, was key.

With regards to skills, we analyzed our data across all programs, looking at six skills in particular: (1) Tooling and machining, (2)
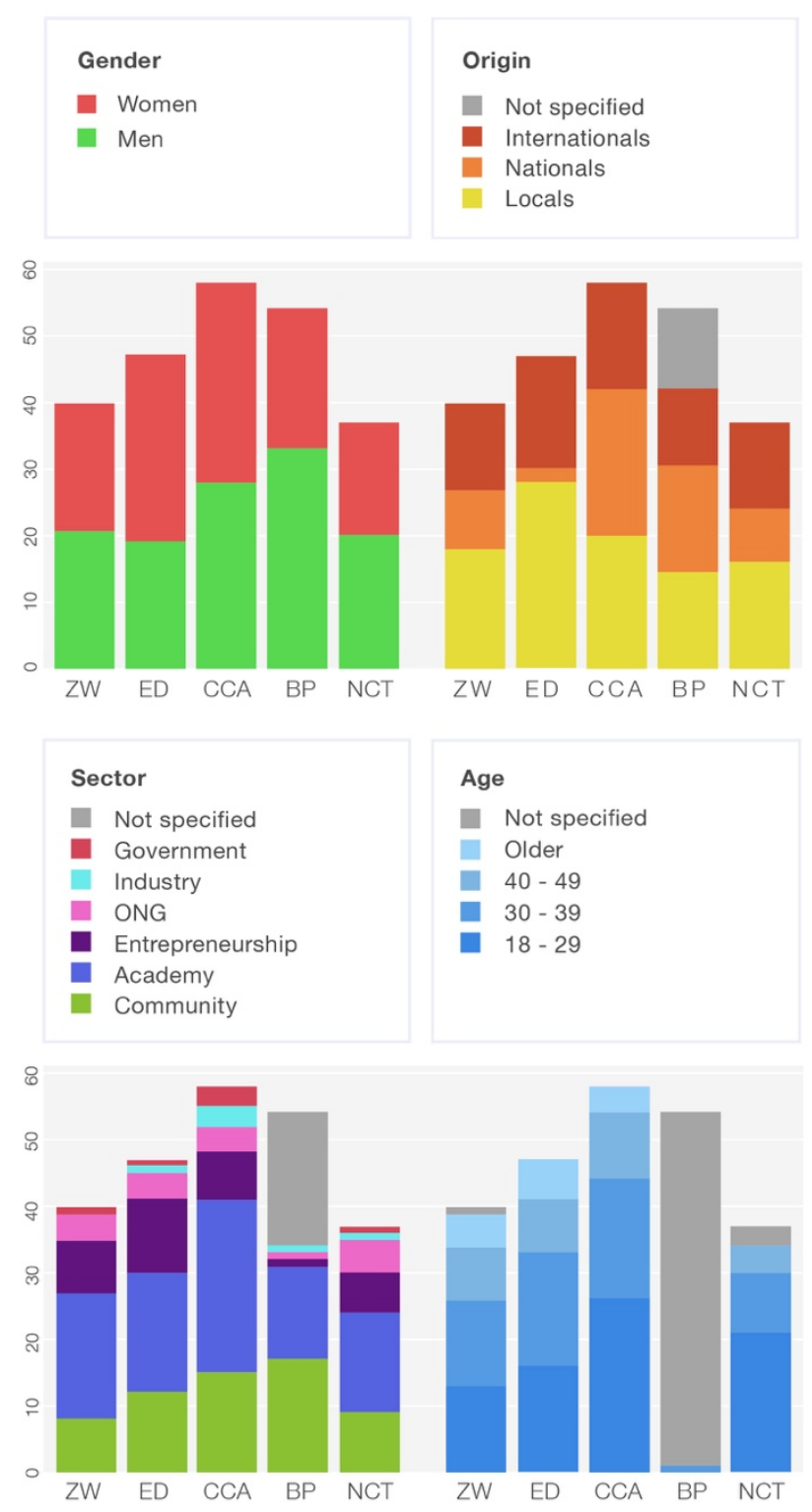

Figure 2: Demographic distribution per summit a) Origin, b) Sector, c) Gender., d) Age

Creative use of materials (personal and professional gains), (3) Intercultural collaboration, (4) Information gathering (collaboration gains), and (5) Teaching, and (6) Adaptability (sustainability gains). These questions were asked in the survey using the prompt: "How confident do you feel about. ..", and answered by participants using a Likert scale.

We found a consistent increase in skills across all programs, and across all skills. Figure 4 shows changes across all programs, and changes specific to each program. In this graph it is possible to see that that most variable skills in the middle of all summits were 'Tooling \& machining' and creative use of materials'. This 


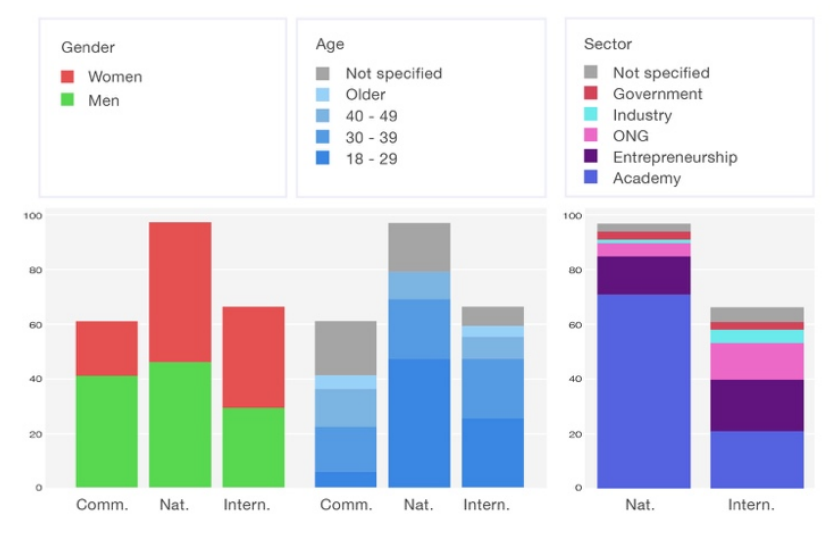

Figure 3: Demographic distribution per Participants' group a) Gender, b) Age, and c) Sector, just for Nationals and Internationals.

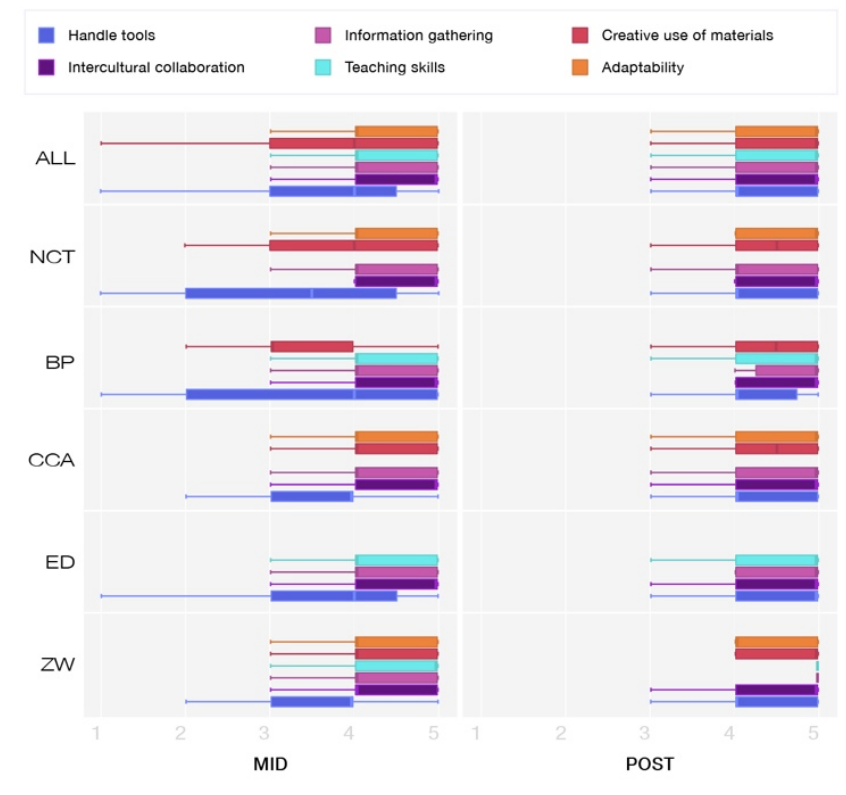

Figure 4: Box plot of participant's skills distribution for each summit. a) In the middle of the IDDS. b) At the end of the IDDS.

means that while some participants reported lacking these skills, others considered themselves as experts. However, at the end of the IDDS, both skills are reported for the participants with medium or high expertise. These show the largest progress with $18.17 \%$ and $13.98 \%$ increase between the mid and post conditions respectively. 'Information gathering', 'teach others', and 'adaptability', were the skills with the highest scores at the end of the program. Table 1 shows all results with regards to skills clustered by participants' demographic characteristics.

We further analyzed how skills changes differed from a gender perspective. This analysis shows that women reported a $3.12 \%$ higher increase in skills than men across all summits. Female participants reported significant increases in technical skills with a $31.40 \%$ increase in their ability to use tools, and $15.66 \%$ increase in their ability to use of creative materials. Interestingly, skills such as intercultural collaboration, and information gathering, which rely on oral communication, do not show notable improvement. This can indicate gender or power dynamics within groups. Men on the other hand, reported the highest increase in skills related to adaptability, information gathering, and creative use of materials. Lastly, and from an age perspective, participants in the 18-32 bracket reported the highest increases in technical skills (tooling and machining, and creative use of materials) with $17,24 \%$ increase, compared with 7,38\% from their 49-older counterparts for example. When comparing these two group ages, our data shows the 18-32 group reporting its lowest progress on intercultural collaboration skills, and the 49-older group reporting its lowest progress on tooling and machining skills. These results can be indicative of generational-based knowledge gaps.

What were the differences across international, national and community participants? We analyzed changes for each set of participants, across all six skills, for all programs. We found that international participants concentrate the majority of the value when looking at progress in skills with $12.60 \%$ increase overall for all five skills, compared with $10.00 \%$ and $6.64 \%$ increase from their national and community counterparts respectively. One reason for these surprising results could be the design itself of the questions coming into the survey. Educational levels, experience, and cultural background, could also play a role. However, given that the data for this analysis comes from a multiple choice, numerical questions, and surveys were administered factoring for participants educational background, it seems reasonable to rule out these reasons. One possible explanation can be differences in self-esteem or selfawareness, where community members assign less value to their learning than international participants for example. International participants were also the group that reported the smallest increase in intercultural collaboration skills with only a $1,32 \%$ across all summits, and the highest increase in both technical skills with a $23.84 \%$ increase in tooling and machining, and a $16.67 \%$, increase in creative use of materials.

On the other hand, community members reported driving the smallest rates of increase with regards to skills with notable exceptions for tooling and machining, and information gathering each with a $10.57 \%$, and $10.77 \%$ increase respectively.

\subsection{Value of the program to communities}

As reported in our previous section, one way in which we measured this value, was through how community members performed during their participation in the program. Another, is how much technological output reached communities.

Community members also reported on their value through openended questions at the end of the program asked with the prompt: "Please share your thoughts around the value of IDDS. What has been most valuable for you?". Participants reported themes around the goals, and collective mechanisms of the program:

Participant 0968: "the interest in making change in communities such as the recyclers community, involving all knowledge in 
Table 1: Averaged progress across skills reported by participants. Pre at the beginning of IDDS, and Post at the end.

\begin{tabular}{|r|cc|c|c|c|c|c|c|c|}
\hline \multirow{2}{*}{ Skills } & \multicolumn{3}{|c|}{ Total } & \multicolumn{5}{c|}{ By Gender } \\
\cline { 2 - 11 } & \multicolumn{3}{|c|}{} & \multicolumn{3}{c|}{ Female } & \multicolumn{3}{c|}{ Male } \\
\cline { 2 - 10 } & Pre & Post & $\mathrm{N}$ & Pre & Post & $\mathrm{N}$ & Pre & Post & $\mathrm{N}$ \\
\hline Tooling \& machining & 3.61 & 4.27 & 160 & 3.14 & 4.13 & 77 & 4.05 & 4.40 & 83 \\
Creative use of materials & 3.92 & 4.47 & 133 & 3.83 & 4.43 & 65 & 4.01 & 4.51 & 68 \\
Intelectual collaboration & 4.47 & 4.58 & 160 & 4.47 & 4.58 & 78 & 4.46 & 4.57 & 82 \\
Information gathering & 4.25 & 4.61 & 159 & 4.38 & 4.57 & 77 & 4.13 & 4.65 & 82 \\
Teach others & 4.27 & 4.67 & 81 & 3.19 & 4.59 & 37 & 4.34 & 4.73 & 44 \\
Adaptability & 4.22 & 4.57 & 112 & 4.24 & 4.47 & 58 & 4.20 & 4.68 & 54 \\
\hline
\end{tabular}

\begin{tabular}{|r|c|c|c|c|c|c|c|c|c|}
\hline \multirow{2}{*}{ Skills } & \multicolumn{9}{|c|}{ By Age } \\
\cline { 2 - 11 } & \multicolumn{3}{|c|}{$\mathbf{1 8 - 3 2}$} & \multicolumn{3}{c|}{$\mathbf{3 3}$ - 48 - Older } \\
\cline { 2 - 11 } & Pre & Post & $\mathrm{N}$ & Pre & Post & $\mathrm{N}$ & Pre & Post & $\mathrm{N}$ \\
\hline Tooling \& machining & 3.55 & 4.33 & 78 & 3.57 & 4.23 & 47 & 4.11 & 4.28 & 18 \\
Creative use of materials & 4.02 & 4.52 & 64 & 3.91 & 4.41 & 34 & 4.31 & 4.77 & 13 \\
Intelectual collaboration & 4.60 & 4.62 & 77 & 4.40 & 4.48 & 48 & 4.39 & 4.72 & 18 \\
Information gathering & 4.25 & 4.57 & 77 & 4.34 & 4.68 & 47 & 4.00 & 4.61 & 18 \\
Teach others & 4.39 & 4.77 & 31 & 4.35 & 4.65 & 23 & 4.33 & 4.75 & 12 \\
Adaptability & 4.30 & 4.66 & 64 & 4.21 & 4.52 & 33 & 4.08 & 4.25 & 12 \\
\hline
\end{tabular}

\begin{tabular}{|r|c|c|c|c|c|c|c|c|c|}
\hline \multirow{2}{*}{ Skills } & \multicolumn{10}{|c|}{ By Origin } \\
\cline { 2 - 11 } & \multicolumn{3}{|c|}{ National } & \multicolumn{3}{c|}{ International } & \multicolumn{3}{c|}{ Communities } \\
\cline { 2 - 11 } & Pre & Post & $\mathrm{N}$ & Pre & Post & $\mathrm{N}$ & Pre & Post & $\mathrm{N}$ \\
\hline Tooling \& machining & 3.58 & 4.24 & 76 & 3.44 & 4.26 & 50 & 3.97 & 4.39 & 31 \\
Creative use of materials & 3.97 & 4.52 & 62 & 3.75 & 4.38 & 40 & 4.22 & 4.52 & 23 \\
Intelectual collaboration & 3.46 & 4.59 & 76 & 4.54 & 4.60 & 50 & 4.35 & 4.52 & 31 \\
Information gathering & 4.33 & 4.68 & 76 & 4.14 & 4.49 & 49 & 4.19 & 4.65 & 31 \\
Teach others & 4.33 & 4.69 & 36 & 4.04 & 4.58 & 24 & 4.47 & 4.84 & 19 \\
Adaptability & 4.29 & 4.64 & 56 & 4.05 & 4.54 & 37 & 4.44 & 4.42 & 18 \\
\hline
\end{tabular}

order to boost access to technologies in accordance to needs. We were one thinking one only family".

Participant 0878: "first, the co-creation and second the sharing of empirical and theoretical knowledge. It values the knowledge one has as fisherman, and scientists or professionals share their theoretical knowledge and we mutually provide feedback to each other".

But the majority of participants reported valuing the intercultural aspect of the experience:

Participant 3395: "Sharing with people from other nationalities, interact, work, dialogue, argue, etc, has been very enriching and I will never forget it".

Participant 0693: "The fact that you can share with other people and learn about other cultures".

Also, as part of our data exploration, we used textual analysis techniques in order to explore dimensions of sentiment related to community members across projects in particular. We used a Natural Language Understanding service from the IBM Watson platform. Sentiment was captured by looking at the responses to the prompt: "Based on your experience, what worked well with the projects, what can be improved?". The sentiment on participants' textual data is detected in relation with its polarity on a scale from -1 to 1 : -1 when the text has negative sentiment, 0 when it's neutral and 1 when the text contains positive expressions. Figure 6 shows how the NCT and ZW programs have the most positive average sentiment scores detected on commentaries from community members. Yet, the sentiment scores present less variation on the NCT program, suggesting that participants in the ZW program had less homogeneous experiences. Also, noticeable how the ED program has the least variation but most comments on the ED summit show neutral or positive sentiments, compared to CCA or ZW programs' scores. Further analyses looking at participants' self-reports of specific pieces of the curriculum can help untangle these observations.

\subsection{Value of co-productions to community partners}

For this dimension of analysis around value, we report results around the most prominent outcome of the program: coproductions. We define the value of co-productions based on how long the project remained active after the program ended. Active in this context is defined as continuity of a project either in the same form as during the summit, or in the form of a different project, as long as its members and/or communities remain the same.

What can be said about the value of the co-productions for community partners? First, it is to be said that during five summits, 40 prototypes were developed, with 6 of them falling into nontechnological categories (e.g. design of eco-touristic services, and pedagogical material). According to the problem/opportunity participants aimed to address, these prototypes were annotated into 9 categories: waste (9), water (2), sanitation (1), agriculture (8), energy (4), education (7), tourism (3), infrastructure (4), and business (2). Seen through the lens of collaboration gains, the breadth of technological co-designs throughout the programs represents tangible value. In order to confirm this proposition, we use textual analysis results of self-reported open-ended questions to the prompt: "In general, how do you feel about your project", collected at the middle and final points of the program.

Results shown in Figure 56 suggest an overall positive sentiment towards projects. When seen through the different kinds of participants, national participants felt the same about their projects at both the mid and final point of the program, international participants sentiment perception did increase. On the other hand, community members seemed to feel less positive about their projects at the end of the program. On top of this, an observation of the words used to refer to co-productions at the mid and post points of the program show a shift in concepts, and the presence of multiple collaboration gains (e.g. team, community, communication).

Both of these findings are consistent with our observations related to the value international participants reported across the skills dimension. We added to this, a metric looking at how long participants who were involved in these or other derivative projects. Figure 7 summarizes these results. From a sustainability gains perspective, it is worth noting that there doesn't seem to be any correlation between aspects surrounding skills development, nor value associated with communities, and how long a project is sustained. In order to explore this question more, we looked at ratings coming from participants regarding some of the key curriculum activities for each summit. Although no correlation can be claimed, it is worth noting that summits with consistently positive scores (ZW and ED), also show longer periods of sustainability for projects.

Lastly, it is worth noting trends in relation to what challenges/opportunities were co-productions aimed at addressing. Waste, agriculture, and education were the most prominent areas of work with 24 projects in total between all three categories. Interestingly, key areas of work such as water, sanitation and energy, had a relatively low footprint with regards to this with only 7 projects 


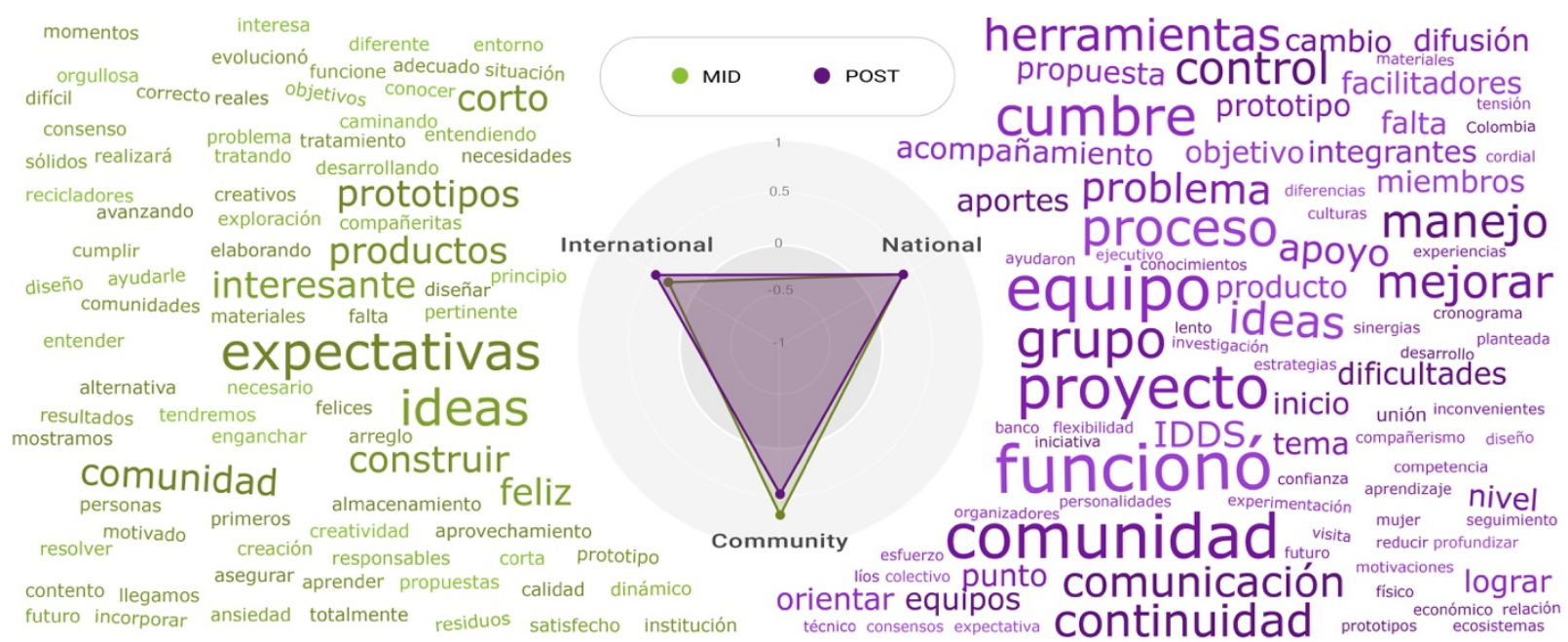

Figure 5: Participants sentiment and word analysis on answers to an open-ended question regarding self-perception of their projects at MID \& POST stages during the program. The data used to produce both sentiment scores for each participants' group is displayed in two clouds of words, the green shows terms found in the report at the middle point of the summits, and the violet the terms found at the end of the summits

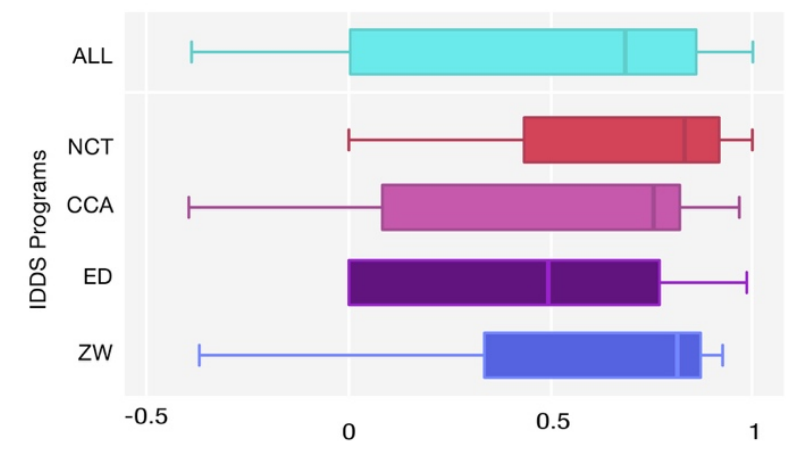

Figure 6: IDDS value's perception of community members through the summit. The BP summit was not included due to insufficiency.

total. One notable absence across all summits, were projects focused on health. This might be due to the specific technical requirements these projects usually have.

\subsection{Unintended outcomes of the IDDS program}

One last set of findings to include, are related with outcomes that were not part of the design of the program per se, but were referenced by program organizers we spoke to in preparation for this paper. This information was triangulated with notes from debriefing sessions held with design facilitators and program organizers at the end of each program. The first, most notable unintended outcome was the establishment of a grassroots organization, following the implementation of the 2015 original program. The formation of this entity was not considered as part of the original design in
2015. One of the main goals of this organization is to continue and expand on the work one within the context of the IDDS programs.

To date, several participants and organizers of this seminal program, remain engaged in the organization, as well as in the advancement of the IDDS program in Colombia, and in other countries in Latin America. Moreover, this organization has been one of the main stakeholders driving the implementation of the majority of the IDDS programs that followed. Over time, the core curriculum of the program has evolved to integrate and embrace the role of the organization.

The second unintended outcome, relates to the continuity component of each of the programs we report on this paper. Using the infrastructure of this grassroot organization, projects developed in the context of the summit can be connected with partners locally and abroad. Early organizers of the IDDS program in Colombia, report continuous work in 2019 on projects developed during the 2017 program. This ongoing support to projects and communities that participated in IDDS programs, comes in the form of collaborations with industry, government, university students, and practitioners in the context of research and educational programs. Interestingly, some particular cases have seen collaborations coming full circle, with communities and/or projects connected back to the MIT D-Lab.

\section{DISCUSSION AND REFLECTION}

We introduced an approach to understanding participation, in the context of community-based PD programs, as a function of outcomes observed from participants, partner communities, and coproductions both during and after the program. But what do these results tell us about the value of the "co"?

First, our data shows that these kinds of community-based PD programs do in fact drive value for actors directly involved in them. From an educational perspective, the steady increase in self-reports 


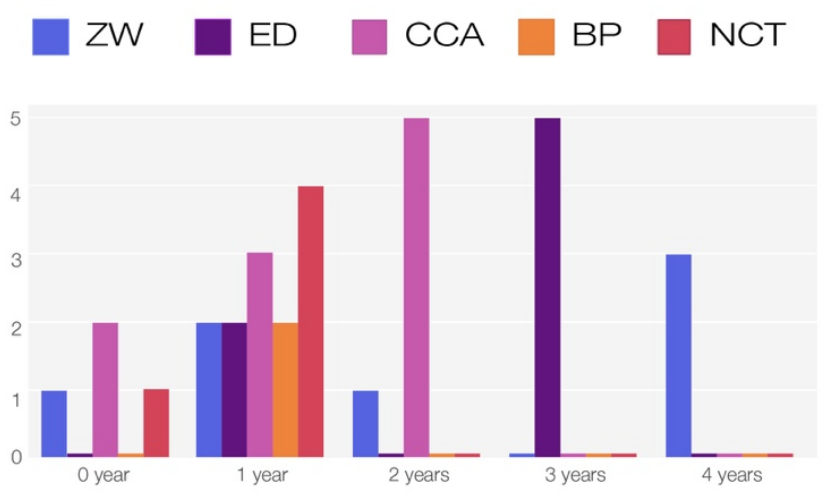

Figure 7: Time the projects have remained active after each program was over.

around skill improvement speaks to the achievement of the program's learning goals. Interestingly, in the case of participants, this value seems to be concentrated in the international participants group. This finding is inconsistent with the design of the program, but it opens an important conversation around how this unintended concentration of value can be embedded in future program designs. Also related to the design of the program, we found that female participants reported the highest improvement in the development of technical skills, and the lowest in relationship to oral-communication based skills. The former observation is consistent to what has been reported in the literature in relationship to technology design gender bias [23, 24]. The latter observation though, appears to relate to gender dynamics expressed in the context of design teams. This finding is aligned with prior work depicting potential gender biases within collaboration [22]. Further exploration is necessary, but the finding itself begs the question of how this might be addressed directly in the design of the program. Lastly, differences in progress between the '18-32' and the '49-older' age brackets, can point to links between age and learning [11], but also to inter-generational gaps. This observation can inform future program design catering to this disparity.

Second, taken together, all aspects of value for local communities that we analyzed in the context of this paper, seem to drive significant value to this group. Even though, under the metrics we used to quantify value for participants in this paper, community members reported not being the most benefited among the full group of participants, the technological output, the value they express to have drawn individually, and the emergence of channels for continuity, seem to be all expressions of value associated with the "co-". One important insight we drive from this surprising result is that our proposed model for evaluation is not directly surfacing these gains. We recognize that our decision to pursue quantifiable gains creates this gap. Is it enough? Further studies are necessary to determine the relationship cost vs. benefit in the context of these programs, not only through the lens of local community stakeholders, but from all stakeholders involved. Furthermore, this finding opens the opportunity for future program designs to address this paradox by modifying existing curriculum to ensure driving more value to community participants under the current model. Another important insight we drive from this surprising result is that our proposed model for evaluation is not directly surfacing these gains. Further exploration of our dataset using qualitative techniques, can provide additional insights.

We set out to explore quantifiable ways to untangle participation, or what we referred to as the "co". By examining in detail outcomes within three prominent dimensions of a community-based PD program, we began to explore new ways to observe how participation happens. In addition, our choice for this approach, as well as the findings we were able to yield, represent a direct response to both Cleaver and Halskov \& Hansen call for more longitudinal studies. Consequently, positioning participation both as a function of longterm engagement in a program seeking to promote and support self-determination, and as a function of outcomes related to the specific advancement of such program, help broadening current notions of participation, specifically within co-design [37].

\section{CONCLUSIONS}

Understanding outcomes and impact are necessary dimensions of the work done within PD. In this paper, we focused on quantifying participation in community-based PD as a key mechanism to understanding how these programs unfold. We presented a multidimensional analysis focused on untangling this notion. By looking at benefits across participants, community partners and coproductions, and across multiple scales, we provided a framework to further study participation. This is of particular importance as it provides insights both into the theory and practice of PD.

In the spirit of adding to the longitudinal body of work in the PD literature, we presented findings looking at a multi-year program over the span of four years, and the implementation of five different iterations of the program. This approach allowed us to uncover how maximizing impact for participants, and in particular for community partners, is not easy. However, it also allowed us to develop data-driven insights into the practice of $\mathrm{PD}$, with implications for future community-based PD programs and assessments. Further studies could expand on this framework, by adding participants assessment across the curriculum, controlling for the quality of education variable.

We also explored the positioning of a program across the instrumental and transformative axis of participation, following up on Sabiescu's conceptualization [36], and how one can go about assessing such an intervention. This contribution opens up space for further programs, focused on creating the necessary mechanisms to provide benefits across these two axes. Overall, our study broadens the spectrum of interventions looking at implementing community programs informed by PD theory, practice, and evidence.

\section{ACKNOWLEDGMENTS}

First, we want to thank all community members who collaborated with us during these five years of work. Although these groups face incredible challenges, they opened the doors of their communities, honored us with their trust, and worked in commonality and openness. We thank the MIT D-Lab, particularly Amy Smith and Sher Vogel, for their leadership in curriculum design and program coordination, as well as to the IDIN team for their support monitoring and evaluation. We want to thank all organizers of IDDS during 
the past five years for volunteering their work and commitment to help design and implement the program in Colombia, and more importantly, for making this work a movement rather than just a program. Lastly, we thank all institutions and collectives who partnered with us to support the IDDS program. This work was possible thanks to these and many other contributions.

\section{REFERENCES}

[1] Ackermann, E., 2001. Piaget's constructivism, Papert's constructionism: What's the difference. Future of learning group publication, 5(3), p.438.

[2] Al-Kodmany, K., 2001. Bridging the gap between technical and local knowledge: Tools for promoting community-based planning and design. Journal of Architectural and Planning research, pp.110-130.

[3] Andersen, L.B., Danholt, P., Halskov, K., Hansen, N.B. and Lauritsen, P., 2015. Participation as a matter of concern in participatory design. CoDesign, 11(3-4), pp.250-261.

[4] Barcellini, F., Prost, L., Cerf, M., 2015. Designers' and users' roles in participatory design: What is actually co-designed by participants? Applied Ergonomics 50, 31-40. https://doi.org/10.1016/j.apergo.2015.02.005

[5] Blake, E.H., Tucker, W.D., Glaser, M. and Freudenthal, A., 2011. Deaf telephony: community-based co-design. Interaction design: beyond human-computer interaction, 3, pp.412-413.

[6] Block, J., 1982. Assimilation, accommodation, and the dynamics of personality development. Child development, pp.281-295.

[7] Bossen, C., Dindler, C. and Iversen, O.S., 2010, November. User gains and PD aims: assessment from a participatory design project. In Proceedings of the 11th Biennial Participatory Design Conference (pp. 141-150). ACM.

[8] Chamberlain, A., Crabtree, A. and Davies, M., 2013, June. Community engagement for research: contextual design in rural CSCW system development. In Proceedings of the 6th International Conference on Communities and Technologies (pp. 131-139). ACM.

[9] Christiansson, J., Grönvall, E. and Yndigegn, S.L., 2018, August. Teaching participatory design using live projects: critical reflections and lessons learnt. In PDC (1) (pp. 8-1).

[10] Cleaver, F., 1999. Paradoxes of participation: questioning participatory approaches to development. Journal of International Development: The Journal of Development Studies Association, 11(4), pp.597-612.

[11] Curran, T., 1997. Effects of aging on implicit sequence learning: Accounting for sequence structure and explicit knowledge. Psychological research, 60(1-2), pp.24-41.

[12] Daes, E.I., 1986. Native people's rights. C. de D., 27, p.123.

[13] Daes, E.I.A., 1993. Some Considerations on the Right of Indigenous Peoples to Self-Determination. Transnat'l L. \& Contemp. Probs., 3, p.1.

[14] Declaration on the Granting of Independence to Colonial Countries and Peoples. 1961. G.A. Res. 1514, U.N. GAOR, 15th Sess., Supp. No. 16, at 66, U.N. Doc. A/4684

[15] DiSalvo, C., Lukens, J., Lodato, T., Jenkins, T. and Kim, T., 2014, April. Making public things: how HCI design can express matters of concern. In Proceedings of the 32nd annual ACM conference on Human factors in computing systems (pp. 2397-2406). ACM.

[16] Dressler, W.W., 1993. Commentary on "Community research: Partnership in Black communities". American Journal of Preventive Medicine, 9(6), pp.32-34.

[17] EWB International, 2016. EWB International. [online] Available at: http://ewbinternational.com/ [Accessed 2 Sep. 2019].

[18] Farquhar, J.W., Fortmann, S.P., Flora, J.A., Taylor, C.B., Haskell, W.L., Williams, P.T., Maccoby, N. and Wood, P.D., 1990. The Stanford Five-City Project: Effects of community-wide education on cardiovascular disease risk factors. Journal of the American Medical Association, 264, pp.359-365.

[19] Final Act of the Conference on Security and Cooperation in Europe. 1975. Adopted Aug. 1, 1975, Dep't St. Pub. No. 8826, reprinted in 14 I.L.M. 1292.

[20] Freire, P., 2000. Pedagogy of the oppressed, 30th anniversary ed. ed. Continuum, New York.

[21] Fuller, J., Bartl, M., Ernst, H. and Muhlbacher, H., 2004, January. Community based innovation: a method to utilize the innovative potential of online communities. In 37th Annual Hawaii International Conference on System Sciences, 2004 Proceedings of the (pp. 10-pp). IEEE.

[22] Gartner, J., Wagner, I., 1996. Mapping Actors and Agendas: Political Frameworks of Systems Design and Participation. Human-Computer Interaction 11, 187-214. https://doi.org/10.1207/s15327051hci1103_1

[23] Gaughan, M. and Bozeman, B., 2016. Using the prisms of gender and rank to interpret research collaboration power dynamics. Social Studies of Science, 46(4), pp.536-558.

[24] Gilles, K. and Feldman-Jacobs, C., 2012. When technology and tradition collide: From gender bias to sex selection. Population Reference Bureau.

[25] Halskov, K. and Hansen, N.B., 2015. The diversity of participatory design research practice at PDC 2002-2012. International Journal of Human-Computer Studies, 74, pp.81-92.

[26] Idin.org, 2016. IDDS 2007 at MIT | International Development Innovation Network. [online] Available at: http://www.idin.org/blog-news-events/events/idds2007-mit [Accessed 2 Sep. 2019].

[27] Israel, B.A., Schulz, A.J., Coombe, C.M., Parker, E.A., Reyes, A.G., Rowe, Z. and Lichtenstein, R.L., 2019. Community-based participatory research. Urban Health, p.272.

[28] Itin, C.M., 1999. Reasserting the philosophy of experiential education as a vehicle for change in the 21st century. Journal of experiential Education, 22(2), pp.91-98.

[29] Kim, B., 2001. Social constructivism. Emerging perspectives on learning, teaching, and technology, 1(1), p.16.

[30] Kristensson, P., Matthing, J., Johansson, N., 2008. Key strategies for the successful involvement of customers in the co-creation of new technology-based services. Int J of Service Industry Mgmt 19, 474-491. https://doi.org/10.1108/ 09564230810891914

[31] Leary, J., 2010, February. Putting Research into Practice: From a Steel City Drawing Board to the Heart of the Maya. In The University of Sheffield-EWB-UK National Research Conference (pp. 1-7).

[32] Manzini, E., Rizzo, F., 2011. Small projects/large changes: Participatory design as an open participated process. CoDesign 7, 199-215. https://doi.org/10.1080/ 15710882.2011.630472

[33] Michael, Y.L., Farquhar, S.A., Wiggins, N. and Green, M.K., 2008. Findings from a community-based participatory prevention research intervention designed to increase social capital in Latino and African American communities. Journal of Immigrant and Minority Health, 10(3), pp.281-289.

[34] MIT D-Lab, 2019. [online] Available at: http://d-lab.mit.edu [Accessed 2 Sep. 2019].

[35] Olin College of Engineering, 2017. Affordable Design \& Entrepreneurship (ADE). [online] Available at: http://meet.olin.edu/olin-isms/affordable-designentrepreneurship-ade [Accessed 2 Sep. 2019].

[36] Sabiescu, A.G., David, S., van Zyl, I. and Cantoni, L., 2014, October. Emerging spaces in community-based participatory design: reflections from two case studies. In Proceedings of the 13th Participatory Design Conference: Research Papers-Volume 1 (pp. 1-10). ACM.

[37] Sadler, P.M., Coyle, H.P., Schwartz, M., 2000. Engineering Competitions in the Middle School Classroom: Key Elements in Developing Effective Design Challenges. Journal of the Learning Sciences 9, 299-327. https://doi.org/10.1207/ S15327809JLS0903_3

[38] Sanders, E.B.N. and Stappers, P.J., 2008. Co-creation and the new landscapes of design. Co-design, 4(1), pp.5-18.

[39] Schön, D.A., 2017. The reflective practitioner: How professionals think in action. Routledge.

[40] Schumacher, E.F. and Schumacher, V., 1996. Buddhist economics. Valuing the earth: economics, ecology, ethics.

[41] Southern, J., Ellis, R., Ferrario, M.A., McNally, R., Dillon, R., Simm, W. and Whittle, J., 2014. Imaginative labour and relationships of care: Co-designing prototypes with vulnerable communities. Technological Forecasting and Social Change, 84, pp.131-142.

[42] Ssozi-Mugarura, F., Blake, E. and Rivett, U., 2016, August. Supporting community needs for rural water management through community-based co-design. In Proceedings of the 14th Participatory Design Conference: Full papers-Volume 1 (pp. 91-100). ACM.

[43] Stager, G.S., 2006. An investigation of constructionism in the Maine Youth Center (Doctoral dissertation, University of Melbourne, Department of Education).

[44] Stanford.edu, 2019. Design for Extreme Affordability. [online] Available at: https: //extreme.stanford.edu/ [Accessed 2 Sep. 2019].

[45] Stewart, F., Deneulin, S., 2002. Amartya Sen's contribution to development thinking. St Comp Int Dev 37, 61-70. https://doi.org/10.1007/BF02686262

[46] Taha, K.A., 2011. Creative capacity building in post-conflict Uganda (Doctoral dissertation, Massachusetts Institute of Technology).

[47] Thinyane, M., Bhat, K., Goldkind, L. and Cannanure, V.K., 2018, August. Critical participatory design: reflections on engagement and empowerment in a case of a community based organization. In Proceedings of the 15th Participatory Design Conference: Full Papers-Volume 1 (p. 2). ACM.

[48] Winschiers-Theophilus, H., Winschiers-Goagoses, N., Rodil, K., Blake, E., Zaman, T., Kapuire, G.K. and Kamukuenjandje, R., 2013. Moving away from Erindiroukambe: Transferability of a rural community-based co-design. IFIIP WG, 9 , pp.363-374. 